\section{Heterogeneity of outcomes in schizophrenia}

\author{
3-year follow-up of treated prevalent cases \\ MIRELLA RUGGERI, ANTONIO LASALVIA, MICHELE TANSELLA, \\ CHIARA BONETTO, MARIA ABATE, GRAHAM THORNICROFT, \\ LILIANA ALLEVI and PAOLA OGNIBENE
}

\author{
Background Care for people with \\ schizophrenia should address a wide range \\ of outcomes, including professional and \\ consumer perspectives.
}

\begin{abstract}
Aims To measure changes in psychopathology, functioning, needs for care and quality of life; to develop predictive models for each outcome domain; and to assess the frequency of 'good' and 'poor' outcomes, as defined in a series of different definitions that use combinations of the four domains measured.
\end{abstract}

\begin{abstract}
Method Three-year follow-up of a I-year-treated prevalence cohort of 107 patients with an ICD-10 diagnosis of schizophrenia attending the South Verona community-based mental health service.
\end{abstract}

\section{Results Mean symptom severity and} some types of needs for care worsen, but quality of life shows no change. Functioning shows a non-significant trend to deteriorate. Between $32 \%$ and $42 \%$ of the variance in the four key outcomes was explained by our model. Different definitions of 'good' and 'poor' outcome included $0-31 \%$ of patients, depending on the definition used.

\section{Conclusions The 3-year outcome for schizophrenia depends on the domain of outcome used, whether staff or patient ratings are used and the stringency of the definitions used for good and poor outcome.}

\section{Declaration of interest None. The} study has been supported by a grant from Fondazione Mario Lugli (Roma).
Schizophrenia is a severe and disabling disorder. So far, most prospective outcome studies in the medium (Jablensky et al, 1992; Leff et al, 1992; Vázquez-Barquero et al, 1999; Singh et al, 2000) and long term (Harrow et al, 1997; Wiersma et al, 1998a; Harrison et al, 2001) have focused on psychopathology and functioning only (Carpenter \& Strauss, 1991; Mason et al, 1996) and have not addressed patient-rated outcomes. In fact, this contrasts with the view that modern mental health care should use a multiple-perspective approach to outcome measurement (Institute of Medicine, 2001). Community-based mental health services based on the principles of continuity of care and integration of pharmacological, psychological and psychosocial treatments are now understood to be the most appropriate type of intervention to ensure the best possible outcome for patients with schizophrenia, and to be those more likely to preserve an acceptable quality of life (Lehman \& Steinwachs, 1998; Drake et al, 2000). Nevertheless, they have been shown to have lower effectiveness in reducing social disability and needs for care (Leese et al, 1998; Wiersma et al, 1998b; Boardman et al, 1999) than in reducing symptoms.

\section{Study aims}

The first aim of this study was to evaluate prospectively the 3-year outcomes, in terms of four outcome domains (symptoms, functioning, needs and quality of life), for a cohort of patients with schizophrenia who received integrated community-based care and to identify the domains likely to improve or worsen over time. The hypotheses tested in relation to this first study aim were that at the level of the whole cohort there would be no significant deterioration in terms of psychopathology and subjective quality of life and there would be significant deterioration in terms of functioning and patient-rated needs. Further, at the level of individual patients, we assessed the proportion of patients who would change their status for symptoms and functioning (staff-rated) and for needs and subjective quality of life (patient-rated) when each outcome domain was considered separately. The second aim of the study was to develop a model to predict the outcomes for individuals with schizophrenia in such non-experimental clinical settings. The third aim was to undertake exploratory analyses to assess the frequency of occurrence of 'good' and 'poor' outcome for this cohort. For this purpose a series of different definitions of 'good' and 'poor' outcome at 3 years were considered that used particular combinations of the four outcome measures.

\section{METHOD}

\section{Study design}

This was a 3-year follow-up study of a cohort of patients with a diagnosis of schizophrenia who where in contact with the South Verona community-based mental health service (CMHS) in 1997 (1-yeartreated prevalence cohort). Baseline assessments were those performed at the Verona site within the context of the EPSILON Study (Becker et al, 1999).

\section{Case identification}

The EPSILON Study used the following inclusion criteria: adults aged 18-65 years inclusive with an ICD-10 (World Health Organization, 1992) research diagnosis of schizophrenia (F20 code, corresponding to 295 DSM-IV code). The exclusion criteria were current residence in prison, secure residential services or hostels for long-term patients, coexisting learning disability ('mental retardation'), primary dementia or other severe organic disorder and extended in-patient treatment episodes longer than 1 year. Full details on sample selection have been published elsewhere (Becker $e t a l$, 1999). In the Verona sample, application of these criteria led to exclusion of only one patient who, although in contact with the South Verona service, was living in a hostel for long-term patients.

In the first stage of the study an administrative prevalence sample of people with a diagnosis of schizophrenia or other psychotic disorders attending the South Verona CMHS (ICD-10, F20-F25) was initially identified from the South Verona Psychiatric Case Register. Cases identified were then diagnosed using the Item Group Checklist of the Schedule for Clinical 
Assessment in Neuropsychiatry (SCAN; World Health Organization, 1992). Only patients with an ICD-10 research diagnosis of schizophrenia were finally included as cases.

\section{Baseline assessment}

The instruments used at baseline were the official, standardised Italian versions of the Brief Psychiatric Rating Scale, Expanded Version (BPRS; Ventura et al, 1993), the Global Assessment of Functioning (GAF; American Psychiatric Association, 1987), the Camberwell Assessment of Need (CAN; Slade et al, 1999) and the Lancashire Quality of Life Profile (LQoLP; Oliver, 1991). The latter two scales were the standardised European Union versions and all scales were known to have high levels of reliability, as demonstrated in the EPSILON Study (Gaite et al, 2000; McCrone et al, 2000). All patients were interviewed only after informed consent had been gained in each case. The procedure used was that research staff explained the purpose of the study and gave full details to each patient in writing, making it clear that participation was entirely voluntary. We told potential subjects that they could choose whether to agree to participate, to decline or to agree and then withdraw at a later time, without any detriment to their clinical care. Confidentiality was fully preserved.

\section{Psychopathology}

Psychopathology was measured by the BPRS (Lukoff et al, 1986; Ventura et al, 1993), which consists of 24 items rated on a seven-point Likert scale $(1=$ no symptom; 7=extremely severe symptom). As shown in a factor analysis performed on a sample of patients with schizophrenia drawn from a multi-centre European Study (further details available from the authors upon request), items cover four dimensions: anxiety/depression (constituted by six items: somatic concern, anxiety, depression, suicidality, guilt, tension); positive symptoms (five items: grandiosity, suspiciousness, hallucinations, unusual thought content, conceptual disorganisation); negative symptoms (seven items: blunted affect, emotional withdrawal, motor retardation, uncooperativeness, self-neglect, disorientation, mannerisms); and mania (hostility, elevated mood, bizarre behaviour, self-neglect, uncooperativeness, excitement, distractibility, motor hyperactivity, mannerisms).

\section{Functioning}

Functioning was measured by the GAF scale (Endicott et al, 1976), which is a measure of individual functioning that includes the impact of symptoms and disability. Functioning is measured on a continuous scale from zero, which denotes extremely severe dysfunction, to 90 , which denotes extremely good function.

\section{Needs for care}

The assessment of needs was made using the CAN, Patient Version. It is an instrument of known and acceptable reliability (Slade et al, 1999) that comprises 22 individual areas grouped into five domains of needs: health (constituted by seven areas: physical health, psychotic symptoms, drugs, alcohol, safety to self, safety to others, psychological distress); basic (three areas: accommodation, food, daytime activities); social (three areas: sexual expression, company, intimate relationships); service (four areas: information, telephone, transport, benefits); and functioning (five areas: basic education, money, child care, self-care, looking after home). Needs are assessed on a three-point scale: $0=$ no problem; $1=$ met problem; $2=$ unmet problem.

\section{Subjective quality of life}

The LQoLP elicits objective quality-of-life indicators and subjective quality-of-life appraisal through patients' answers to interviewer-administered questions concerning nine dimensions: work/education, leisure/participation, religion, finances, living situation, legal and safety, family relations, social relations, and health. Each question allows patients to rate their satisfaction on a seven-point life satisfaction scale $(1=$ cannot be worse, $7=$ cannot be better). The average of the resulting nine dimension scores is referred to as the perceived quality of life.

The LQoLP includes two scales for the measurement of affect balance and selfesteem, each constituting of ten items rated on a yes/no categorical scale. The former scale investigates the patient's emotional status by assessing the presence of negative and positive feelings; the latter investigates the patient's view about him- or herself.

\section{Follow-up assessments}

All eligible patients included in the baseline assessment were traced after 3 years and reassessed with the same set of instruments and the same procedures used at baseline. Service utilisation data for the entire baseline to follow-up period were extracted for each individual patient from the South Verona Psychiatric Case Register (Tansella, 1993).

\section{Study setting}

South Verona is a mixed urban and rural area of about 75000 inhabitants that includes part of the city of Verona and two neighbouring small towns. The main agency providing psychiatric care for the adult population is the South Verona CMHS, which is run by the Section of Psychiatry, Department of Medicine and Public Health of the University of Verona. The South Verona CMHS supplies a wide range of comprehensive and well-integrated programmes, including in-patient care, day care, rehabilitation, out-patient care, home visits, a 24-hour emergency service and residential facilities (three apartments and one hostel) for long-term patients. This ensures continuity of care through the different phases of treatment and across the various components of service provision. The South Verona Psychiatric Case Register covers the same geographical area and collects demographic, diagnostic and service utilisation data on all patients seen by public and private ambulatory and hospital specialist mental health services in the Province of Verona.

\section{Statistical methods}

\section{Analysis of changes at follow-up}

Changes in BPRS, LQoLP total and dimensional sub-scores, GAF, CAN, self-esteem and affect balance were first assessed by comparing mean scores at baseline and follow-up using Wilcoxon tests. The application of Bonferroni correction is not possible because most dimensions are correlated, so significance levels are presented without correction. For the purpose of discussion of the results, however, we set the significance level at 0.01 as a compromise to the Bonferroni correction (Pope et al, 2001). Subsequently, we assessed the percentage of subjects who had changes (improvement or worsening) or who maintained their previous status (stability). We have considered as stable a subject with a change not exceeding \pm 0.5 (inclusive) for BPRS and LQoLP, \pm 5 (inclusive) for GAF and \pm 1 (inclusive) for CAN, self-esteem 
and affect balance mean scores. The selection of the cut-off points was based on identification of the minimum measurable change detected by the rating scale. Changes in service utilisation between the year preceding baseline assessment and the 3-year follow-up period were assessed by means of the McNemar and Wilcoxon tests, as appropriate.

\section{Predictors of outcome}

Bivariate relationships between each outcome domain indicator and the independent variables were explored and variables were found to be suitable for regression analysis. To identify the predictors of each outcome domain at 3 years, a series of block-stratified multiple regression models (Ruggeri et al, 2001) was constructed with follow-up scores of each indicator used as the dependent variable. The following baseline independent variables were entered in turn: demographic characteristics (older than 35 years $v$. others; single; higher educational level; living alone $v$. others, shelter $v$. others; employed $v$. others; retired/housewife/student ${ }^{1} v$. others); duration of illness (years); total mean BPRS score; GAF mean score; service utilisation in the baselinefollow-up interval (out-patient and community care contacts; 1-30 day hospital contacts $v$. higher; 1-90 days of admission $v$. others); mean total number of problems detected in the CAN; and mean total LQoLP score. Some variables had to be categorised because of their skewness. Because the follow-up period was not exactly 3 years for all patients, service utilisation variables were standardised to 36 months in order to avoid bias introduced by slightly varying follow-up periods. The standardisation formula was as follows: (number of contacts during the follow-up period/length of follow-up) $\times 36$, months The baseline scores of each indicator were included in the final blocks owing to the strong associations between baseline and follow-up measurements, which could potentially hide important relationships with other variables. In the block-stratified multiple regression model, significant $(P<0.05)$ predictors are selected in the first block; subsequently, the procedure of selection is repeated in the second block, retaining those variables that were significant in

I. 'Housewife' includes both married and unmarried women. the previous block even if they were no longer significant after the new selection. The process goes on until the last block. Only variables surviving all these steps are included in the final models. This procedure permits forcing the entry of certain variables that are important for prediction from a conceptual point of view, which otherwise would be hidden by more correlated predictors. Each $\beta$-coefficient represents a multivariate value (i.e. the contribution of the corresponding predictor to the dependent variable) adjusted for the effect of the other predictors selected by the model. The regression analysis was performed using SPSS for Windows, release 10.0.7.

\section{Multi-dimensional definitions of good and poor outcome at 3-year follow-up}

To explore further the proportion of the cohort that could be considered to have good or poor outcomes after 3 years, we have made a distinction between staff-rated (symptoms and functioning) and patientrated (needs and quality of life) outcomes and then defined a series of conditions that may be combined either for all four outcomes simultaneously or for combinations of possible values within the staff-rated and the patient-rated outcomes, respectively. Eight different options have been considered here as definitions of good outcome and eight different options as definitions of poor outcome (see Tables 7 and 8).

\section{RESULTS}

\section{Baseline assessments}

At baseline, 141 subjects with an ICD-10 SCAN-confirmed F20 diagnosis were identified. They constitute the 1-year-treated prevalence cohort of the South Verona CMHS in 1997. Of these, eight had such a severe psychopathological status that they were not able to participate in the assessment, so there were 133 eligible patients. Twenty-five refused to be interviewed and one was not traceable. A total of 107 participants $(80 \%$ of those eligible) completed all baseline assessment scales and constitute the baseline cohort.

\section{Follow-up assessments}

At the 3-year follow-up, among the 107 subjects belonging to the baseline cohort 5 people had died. Of the 102 eligible ones, 1 was not traceable and 6 refused to be interviewed at follow-up. A total of 95 individuals (89\% of the eligible) completed the clinical assessment (GAF and BPRS) both at baseline and at follow-up; 90 completed the CAN and 88 completed the LQoLP. On average, follow-up assessments were performed 36.1 months (s.d. $=5.1$, median $=36.9$, range $=31.9-43.9$ ) after the baseline assessment.

\section{Socio-demographic and service utilisation data}

Socio-demographic and clinical characteristics of the baseline cohort are given by Gaite et al (2002). Briefly, the mean age was 42.6 years and $51 \%$ were female. Regarding living conditions, $79.4 \%$ were living with a partner or other family members, $12.2 \%$ were living alone and $8.4 \%$ were in sheltered accommodation. Over one-quarter $(27 \%)$ had a secondary school or higher level of education and $28 \%$ were employed. Service utilisation data (Table 1) in the year preceding baseline assessment and in the follow-up period show that about one-quarter of patients were admitted to hospital each year during both time periods and attended, on average, more than one out-patient visit per week. The use of sheltered apartments (for longstay rehabilitation), day care and domiciliary care all applied to more people over time but with a decreasing intensity of contacts.

\section{Psychopathology}

Baseline and follow-up psychopathological data are given in Table 2, which shows that the total mean scores, and levels of the subscores, indicate relatively low levels of symptoms; analyses conducted at the individual item level showed that unusual thought content (mean baseline score 2.2; s.d.=1.6; 95\% CI 1.88-2.52), anxiety (mean baseline score 2.2; s.d.=1.3; 95\% CI 1.94-2.46) and hallucinations (mean baseline score $2.0 ;$ s.d. $=1.6 ; 95 \%$ CI 1.68-2.32) are the more commonly present and severe symptoms. At the 3-year followup a significant worsening was found in the total mean BPRS score $(P<0.01)$; there were trends for all BPRS sub-scores to become worse at follow-up but only negative symptoms deteriorated significantly $(P<0.01)$. The worsening of negative symptoms was even more marked at the individual BPRS item level, where highly significant deterioration was found for all items that contribute to the negative symptom sub-score (blunted affect $P<0.01$; 
Table I Service utilisation in the year preceding baseline assessment and in the follow-up period ( $n=107$; bold type indicates significant difference)

\begin{tabular}{|c|c|c|c|}
\hline & $\begin{array}{l}\text { Service utilisation in the year } \\
\text { preceding baseline (contacts/year) }\end{array}$ & $\begin{array}{l}\text { Service utilisation in the 3-year } \\
\text { follow-up period (contacts/year)' }\end{array}$ & $P$ \\
\hline \multicolumn{4}{|l|}{ Admission to hospital } \\
\hline Participants with any admission & $25 \%$ & $23 \%$ & $0.824^{3}$ \\
\hline Attenders' number of days in hospital, mean (s.d., range) & $55.3(69.5,7-270)$ & $31.0(39.4,1-135)$ & $0.655^{4}$ \\
\hline \multicolumn{4}{|l|}{ Sheltered apartments } \\
\hline Participants with any admission & $5 \%$ & $6 \%$ & $0.500^{3}$ \\
\hline Attenders' number of days in apartments, mean (s.d., range) & $363.8(4.9,355-366)$ & $263.4(160.3,7-360)$ & $0.157^{4}$ \\
\hline \multicolumn{4}{|l|}{ Day care ${ }^{2}$} \\
\hline Participants with any contact & $49 \%$ & $64 \%$ & $0.003^{3}$ \\
\hline Attenders' number of day care contacts, mean (s.d., range) & $60.5(100.9,1-464)$ & $57.4(116.4,1-577)$ & $0.002^{4}$ \\
\hline Out-patient care (number of contacts) & $66.5(112.0,0-618)$ & $72.2(127.3,0-652)$ & $0.899^{3}$ \\
\hline \multicolumn{4}{|l|}{ Domiciliary care } \\
\hline Participants with any visit & $35 \%$ & $49 \%$ & $0.007^{3}$ \\
\hline $\begin{array}{l}\text { Number of visits by those who received the intervention, } \\
\text { mean (s.d., range) }\end{array}$ & $9.2(12.0,1-49)$ & $3.1(5.2,1-29)$ & $0.004^{4}$ \\
\hline
\end{tabular}

I. Number of contacts have been first standardised to 36 months and then recoded to $I$ year.

2. Day hospital and/or day centre attenders.

3. McNemar test.

4. Wilcoxon test.

emotional withdrawal $P<0.01$; uncooperativeness $P=0.02$; self-neglect $P<0.01$, except for motor retardation $(P=0.88)$, disorientation $(P=0.82)$ and mannerisms $(P=0.56)$.

Table 2 shows (in the three right-most columns) that for the BPRS total score, and its sub-scores, about two-thirds of patients remained symptomatically stable over the 3 -year study period. Where changes did occur, these were more often deteriorations than improvements in mental state. This was especially so for the negative symptom sub-score, and indeed it was the items that contribute to this sub-score that showed the most marked areas of symptomatic deterioration over time and for which, on average, only about one-third of patients were stable.

\section{Functioning}

As shown in the last row of Table 2, the mean level of functioning was relatively low both at baseline (56.5) and at followup (53.4). A relatively substantial mean deterioration for the whole cohort was found but did not reach significance because the large standard variation was unlikely to be able to detect a three-point difference based on a 90 -point rating scale. For individuals, only $23 \%$ of subjects were stable and $47 \%$ deteriorated during the study.

\section{Needs for care}

As shown in Table 3, the total number of needs for care did not differ between baseline and follow-up. At the level of the CAN domains, a decrease in health $(P=0.04)$ and social $(P=0.04)$ needs and an increase in functioning $(P=0.02)$ needs

Table 2 Changes in Brief Psychiatric Rating Scale (BPRS: I=no symptom; 7=extremely severe symptom) and Global Assessment of Functioning (GAF: I=extremely severe dysfunction; $90=$ extremely good function) score over the 3 -year follow-up period ( $n=95$ patients; bold type indicates significant difference, Wilcoxon test)

\begin{tabular}{|c|c|c|c|c|c|c|c|c|}
\hline & \multirow{2}{*}{$\begin{array}{c}\text { Baseline } \\
\text { Mean (s.d.) }\end{array}$} & \multirow{2}{*}{$\begin{array}{l}\text { Follow-up } \\
\text { Mean (s.d.) }\end{array}$} & \multirow[t]{2}{*}{$\Delta(\mathrm{FU}-\mathrm{BL})^{\prime}$} & \multirow[t]{2}{*}{ Effect size $e^{1,2}$} & \multirow[t]{2}{*}{$P$} & \multicolumn{3}{|c|}{ Change in outcome scale } \\
\hline & & & & & & $\begin{array}{c}\text { Worsened } \\
n(\%)\end{array}$ & $\begin{array}{c}\text { Stable }^{3} \\
n(\%)\end{array}$ & $\begin{array}{c}\text { Improved } \\
n(\%)\end{array}$ \\
\hline BPRS total score & $1.5(0.5)$ & $1.6(0.5)$ & -0.1 & -0.3 & 0.011 & $17(18 \%)$ & 70 (74\%) & $8(8 \%)$ \\
\hline Anxiety/depression & I.7 (0.8) & $\mathrm{I} .8(0.7)$ & -0.1 & -0.1 & 0.105 & $21(22 \%)$ & $59(62 \%)$ & $15(16 \%)$ \\
\hline Positive symptoms & $1.8(1.0)$ & $1.9(I . I)$ & -0.1 & -0.1 & 0.505 & $25(26 \%)$ & 49 (52\%) & $21(22 \%)$ \\
\hline Negative symptoms & $1.3(0.4)$ & $1.5(0.7)$ & -0.2 & -0.5 & $<0.0$ I & $26(28 \%)$ & $63(67 \%)$ & $5(5 \%)$ \\
\hline Mania & $\mathrm{I} .2(0.4)$ & $\mathrm{I} .3(0.4)$ & -0.1 & -0.2 & 0.105 & $12(13 \%)$ & 77 (81\%) & $6(6 \%)$ \\
\hline GAF score & $56.5(16.3)$ & $53.4(17.0)$ & -3.1 & -0.2 & 0.086 & 44 (47\%) & $22(23 \%)$ & $28(30 \%)$ \\
\hline
\end{tabular}

BL, baseline; FU, follow-up; $\Delta$, difference.

I. +, improvement in the patient's condition; -, worsening of condition. To obtain this polarity the signs of BPRS values have been inverted.

2. Effect size $=($ mean $\mathrm{FU}-\mathrm{BL}) /$ s.d. BL.

3. For BPRS we have considered as stable a subject with a change not exceeding \pm 0.5 (included); for GAF we have considered as stable a subject with a change not exceeding \pm 5 (included). 
Table 3 Needs at baseline and follow-up according to the Camberwell Assessment of Need (CAN) in the cohort ( $n=90$ patients; bold type indicates significant difference, Wilcoxon test)

\begin{tabular}{|c|c|c|c|c|c|c|}
\hline & All CAN areas & Health & Basic & Social & Service & Functioning \\
\hline \multicolumn{7}{|c|}{ Total needs, mean (s.d.) } \\
\hline Baseline & $4.8(3.2)$ & $1.7(1.2)$ & $0.7(1.0)$ & $1.0(1.0)$ & $0.6(0.8)$ & $0.5(0.8)$ \\
\hline \multirow[t]{2}{*}{ Follow up } & $4.6(3.1)$ & $1.5(1.1)$ & $0.8(0.9)$ & $0.8(0.9)$ & $0.6(0.7)$ & $0.8(1.0)$ \\
\hline & $P=0.417$ & $P=0.042$ & $P=0.198$ & $P=0.038$ & $P=0.983$ & $P=0.021$ \\
\hline \multicolumn{7}{|c|}{ Met needs, mean (s.d.) } \\
\hline Baseline & $3.5(2.8)$ & $1.4(1.0)$ & $0.6(0.9)$ & $0.5(0.7)$ & $0.4(0.6)$ & $0.6(0.9)$ \\
\hline \multirow[t]{2}{*}{ Follow up } & $3.1(2.3)$ & I.I (0.9) & $0.7(0.9)$ & $0.2(0.4)$ & $0.4(0.6)$ & $0.7(0.9)$ \\
\hline & $P=0.129$ & $P=0.032$ & $P=0.217$ & $P=0.001$ & $P=0.730$ & $P=0.360$ \\
\hline \multicolumn{7}{|c|}{ Unmet needs, mean (s.d.) } \\
\hline Baseline & $1.3(1.8)$ & $0.4(0.7)$ & $0.1(0.4)$ & $0.5(0.8)$ & $0.2(0.5)$ & $0.1(0.3)$ \\
\hline \multirow[t]{2}{*}{ Follow up } & $1.5(1.6)$ & $0.4(0.7)$ & $0.1(0.3)$ & $0.6(0.8)$ & $0.2(0.5)$ & I.I (0.4) \\
\hline & $P=0.212$ & $P=0.716$ & $P=0.902$ & $P=0.426$ & $P=0.785$ & $P=0.224$ \\
\hline \multicolumn{7}{|c|}{ Ratio met:unmet } \\
\hline Baseline & 2.7 & 3.7 & 4.4 & 0.9 & 2.1 & 3.7 \\
\hline Follow up & 2.0 & 2.9 & 4.9 & 0.3 & 1.8 & 0.6 \\
\hline
\end{tabular}

was detected. More detailed analysis showed that, at baseline, the needs profile of the cohort had the most favourable ratio between met and unmet needs in basic, functioning and health domains, where met needs were clearly prevailing over unmet needs; on the other hand, in the social domain unmet needs were slightly prevailing over met needs. In all domains the met/unmet proportion tended to be less favourable at follow-up, with the most clear-cut deterioration in the area of functioning needs; basic needs were an exception, with a slight increase in the proportion of met needs at follow-up.

Results of changes in needs for care at the individual patient level are shown in Table 4. A different trend for social needs and all other domains was found. Overall, when needs were absent at baseline they
Table 4 Changes in needs for care that occurred during the follow-up interval according to the Camberwell Assessment of Need (CAN) ( $n=90$ patients)

\begin{tabular}{lcccccc}
\hline & All CAN areas & Health & Basic & Social & Service & Functioning \\
\hline Needs absent at baseline', & $1482(100 \%)$ & $469(100 \%)$ & $207(100 \%)$ & $153(100 \%)$ & $302(100 \%)$ & 351 \\
n (\%) & & & & & & \\
Still absent at follow-up & $87 \%$ & $90 \%$ & $83 \%$ & $84 \%$ & $88 \%$ & $87 \%$ \\
Met at follow-up & $9 \%$ & $9 \%$ & $12 \%$ & $6 \%$ & $8 \%$ & $10 \%$ \\
Unmet at follow-up & $4 \%$ & $1 \%$ & $5 \%$ & $10 \%$ & $4 \%$ & $3 \%$ \\
Needs met at baseline & $309(100 \%)$ & $121(100 \%)$ & $51(100 \%)$ & $42(100 \%)$ & $37(100 \%)$ & $58(100 \%)$ \\
Absent at follow-up & $45 \%$ & $45 \%$ & $31 \%$ & $48 \%$ & $65 \%$ & $43 \%$ \\
Still met at follow-up & $37 \%$ & $35 \%$ & $63 \%$ & $17 \%$ & $14 \%$ & $48 \%$ \\
Unmet at follow-up & $18 \%$ & $20 \%$ & $6 \%$ & $35 \%$ & $21 \%$ & $9 \%$ \\
Needs unmet at baseline ${ }^{3}$ & $113(100 \%)$ & $33(100 \%)$ & $12(100 \%)$ & $41(100 \%)$ & $18(100 \%)$ & $9(100 \%)$ \\
Absent at follow-up & $48 \%$ & $40 \%$ & $67 \%$ & $39 \%$ & $55 \%$ & $67 \%$ \\
Met at follow-up & $27 \%$ & $47 \%$ & $33 \%$ & $7 \%$ & $39 \%$ & $22 \%$ \\
Still unmet at follow-up & $25 \%$ & $13 \%$ & $0 \%$ & $54 \%$ & $6 \%$ & $11 \%$ \\
\hline
\end{tabular}

I. Calculated by summing CAN ratings $=0$ (no need) obtained for the patients of whole cohort in all CAN areas or in the CAN areas included in each domain.

2. Calculated by summing CAN ratings $=$ I (met need) obtained for the patients of whole cohort in all CAN areas or in the CAN areas included in each domain.

3. Calculated by summing CAN ratings $=2$ (unmet need) obtained for the patients of whole cohort in all CAN areas or in the CAN areas included in each domain. tended to remain absent at follow-up; when they were present at baseline (whether met or unmet), a clear general trend towards improvement was detected at follow-up, suggesting that effective treatment had been provided in the interim. In the social domain, however, the majority of patients who had no social needs at baseline also continued to have no needs at follow-up, but when a new social need was detected at follow-up it tended to be more frequently an unmet need. Among those individuals who did have social needs at baseline, most also continued to have these needs at follow-up, indicating that no effective intervention had been applied to these social problems.

\section{Subjective quality of life}

The results of the subjective LQoLP ratings are shown in Table 5. At the cohort level there was no overall pattern of any significant changes, either for the total score or for the domains. At the individual patient level about half of the patients were stable, a quarter worsened and a quarter improved. There were some variations for domains of the subjective LQoLP, particularly for satisfaction with work, where patients more often improved than remained stable. A different trend was found for the two additional scales included in the LQoLP, which measure self-esteem and affect balance. At the individual patient level the trend was similar to the LQoLP domains because about half of the subjects were stable and for self-esteem equal proportions improved or deteriorated, whereas for affect balance there was a tendency towards deterioration.

\section{Predictors of outcome}

\section{Psychopathology}

Lower functioning at baseline and higher number of days in hospital in the followup period were the only variables to predict a higher severity of psychopathology and explained $38 \%$ of variance (see Table 6, column 2). Adding the BPRS baseline scores did not have any additional impact on the variance explained, indicating that after having taken into account the variables included in previous blocks the severity of psychopathology after 3 years was not predicted by its severity at baseline. Moreover, these results show that duration of illness was not a predictor of psychopathological severity over the 3-year follow-up. 
Table 5 Changes in the Lancashire Quality of Life Profile (LQoLP: $I=$ minimum score; $7=$ maximum score), self-esteem and affect balance scales ( $0=$ minimum score; $10=$ maximum score) over the 3 -year follow-up period ( $n=88$ patients; bold type indicates significant difference, Wilcoxon test)

\begin{tabular}{|c|c|c|c|c|c|c|c|c|}
\hline & \multirow{2}{*}{$\begin{array}{c}\text { Baseline } \\
\text { Mean (s.d.) }\end{array}$} & \multirow{2}{*}{$\begin{array}{l}\text { Follow-up } \\
\text { Mean (s.d.) }\end{array}$} & \multirow[t]{2}{*}{$\Delta(\mathrm{FU}-\mathrm{BL})^{\prime}$} & \multirow[t]{2}{*}{ Effect size ${ }^{2}$} & \multirow[t]{2}{*}{$P$} & \multicolumn{3}{|c|}{ Mental state of participants } \\
\hline & & & & & & $\begin{array}{c}\text { Worsened } \\
n(\%)\end{array}$ & $\begin{array}{c}\text { Stable }^{3} \\
n(\%)\end{array}$ & $\begin{array}{c}\text { Improved } \\
n(\%)\end{array}$ \\
\hline LQoLP total score & $4.8(0.8)$ & $4.7(0.9)$ & -0.1 & -0.1 & 0.267 & 21 (24\%) & $50(57 \%)$ & 17 (19\%) \\
\hline Global well-being & $4.5(1.4)$ & $4.4(1.3)$ & 0.0 & 0.0 & 0.500 & $22(25 \%)$ & 47 (54\%) & $18(21 \%)$ \\
\hline Work & $4.1(1.5)$ & $4.5(1.6)$ & +0.4 & +0.3 & 0.065 & 21 (28\%) & $22(29 \%)$ & 33 (43\%) \\
\hline Leisure activities & $4.7(I . I)$ & $4.7(I . I)$ & 0.0 & 0.0 & 0.599 & 31 (36\%) & $30(34 \%)$ & $26(30 \%)$ \\
\hline Religion & $5.3(1.0)$ & $5.0(1.2)$ & -0.3 & -0.3 & 0.030 & $24(32 \%)$ & 41 (54\%) & II (I4\%) \\
\hline Finance & $4.4(1.4)$ & $4.1(1.5)$ & -0.2 & -0.2 & 0.230 & $27(32 \%)$ & $36(43 \%)$ & $21(25 \%)$ \\
\hline Living situation & $4.8(1.0)$ & $4.7(I . I)$ & -0.2 & -0.2 & 0.236 & 27 (31\%) & 40 (46\%) & $20(23 \%)$ \\
\hline Legal and safety & $5.1(1.4)$ & $4.9(1.4)$ & -0.2 & -0.1 & 0.289 & $24(30 \%)$ & $4 I$ (50\%) & $16(20 \%)$ \\
\hline Family relations & $4.9(1.3)$ & $5.0(1.3)$ & +0.1 & +0.1 & 0.431 & 17 (2I\%) & 38 (47\%) & $26(32 \%)$ \\
\hline Social relations & $4.5(I .5)$ & $4.6(1.4)$ & +0.1 & 0.0 & 0.660 & 18 (2I\%) & 49 (56\%) & $20(23 \%)$ \\
\hline Health & $4.9(I . I)$ & $4.8(1.0)$ & -0.1 & -0.1 & 0.517 & $26(31 \%)$ & 38 (45\%) & $20(24 \%)$ \\
\hline Self-esteem & $6.8(2.8)$ & $6.8(2.8)$ & -0.1 & 0.0 & 0.861 & $21(25 \%)$ & 45 (54\%) & 18 (2।\%) \\
\hline Affect balance & $6.2(2.7)$ & $5.6(2.6)$ & -0.6 & -0.2 & 0.041 & $28(33 \%)$ & 42 (49\%) & 15 (I8\%) \\
\hline
\end{tabular}

BL, baseline; FU, follow-up; $\Delta$, difference.

I. + , improvement in the patient's condition; - , worsening of condition.

2. Effect size $=($ mean $\mathrm{FU}-$ mean $\mathrm{BL}) / \mathrm{s.d}$. BL.

3. For LQoLP we have considered stable a subject with a change not exceeding \pm 0.5 (included); for self-esteem and affect balance we have considered stable a subject with a change not exceeding $\pm I$ (included).

Table 6 Longitudinal predictors for psychopathology, functioning, needs for care and quality of life; for each indicator, estimated $\beta$-coefficients and difference-adjusted $R^{2}$ for block I-6 final models and block 7 baseline scores are shown'

\begin{tabular}{|c|c|c|c|c|}
\hline Dependent variable & BPRS follow-up & GAF follow-up & CAN total needs follow-up & LQoLP follow-up \\
\hline \multicolumn{5}{|l|}{ Block I: Socio-demographics at baseline } \\
\hline Gender (male) & & $-0.16(4 \%) \mathrm{NS}$ & & \\
\hline Employment (employed v. others) & & $0.27(8 \%)^{* *}$ & $-0.16(6 \%) \mathrm{NS}$ & \\
\hline \multicolumn{5}{|l|}{ Block 2: Duration of illness at baseline } \\
\hline Years from first contact with our service & & $-0.13(5 \%) \mathrm{NS}$ & & \\
\hline \multicolumn{5}{|l|}{ Block 3: Psychopathology and functioning at baseline } \\
\hline BPRS mean score & - & $-0.10(4 \%) \mathrm{NS}$ & & \\
\hline GAF score & $-0.46(27 \%)^{* *}$ & - & $-0.45(27 \%)^{* *}$ & $0.20(6 \%)$ NS \\
\hline \multicolumn{5}{|l|}{ Block 4: Service utilisation in the 3 -year follow-up period ${ }^{2}$} \\
\hline \multicolumn{5}{|l|}{ Admissions } \\
\hline High no. of days of admission $(>90) v$. others & $0.34(11 \%)^{* *}$ & $-0.26(7 \%)^{* *}$ & & \\
\hline \multicolumn{5}{|l|}{ Block 5: Needs for care at baseline } \\
\hline CAN mean number of problems & & $-0.23(2 \%)^{*}$ & - & $-0.36(6 \%)^{* *}$ \\
\hline \multicolumn{5}{|l|}{ Block 6: Quality of life at baseline } \\
\hline LQoLP mean score & & & $-0.21(3 \%)^{*}$ & - \\
\hline \% Variance explained by blocks I-6 & $38 \%$ & $30 \%$ & $36 \%$ & $12 \%$ \\
\hline \multicolumn{5}{|l|}{ Block 7} \\
\hline The same instrument as dependent variable, but at baseline & & $0.36(5 \%)^{* *}$ & $0.38(6 \%)^{* *}$ & $0.52(20 \%)^{* *}$ \\
\hline$\%$ Variance explained by final model & $38 \%$ & $35 \%$ & $42 \%$ & $32 \%$ \\
\hline
\end{tabular}

BPRS, Brief Psychiatric Rating Scale; GAF, Global Assessment of Functioning; CAN, Camberwell Assessment of Need; LQoLP, Lancashire Quality of Life Profile.

I. Non-significant (NS) values in blocks I-6 indicate that those variables significantly improved the $R^{2}$ of the previous blocks but lost their significance when variables from the further blocks were added.

2. Number of contacts were standardised to 36 months for all patients.

$* P<0.05 ; * * P<0.01$ 


\section{Functioning}

Worse functioning at follow-up (rated by the GAF) was best predicted by male gender, retired/housewife/student, longer history of treatment, higher level of symptoms (BPRS score), more time in hospital during the follow-up period and more needs, which together explained $30 \%$ of the variance (see Table 6, column 3). When baseline GAF was included in the model the variance explained increased to $35 \%$, indicating that follow-up functioning was predicted by baseline functioning level.

\section{Needs for care}

Higher levels of needs at follow-up were significantly predicted by unemployment, lower functioning and lower quality of life, together explaining $36 \%$ of the variance. Baseline total number of needs also contributed to the increase in variance explained in the follow-up and increased the variance explained to $42 \%$ (see Table 6 , column 4).

\section{Quality of life}

Lower quality of life at follow-up was predicted by lower levels of functioning and by more needs, accounting together for $12 \%$ of the variance explained. This was overshadowed by the far greater effect of the baseline LQoLP score, which added a further $20 \%$ to the variance explained (see Table 6, column 5).

\section{Definitions of good and poor outcome at 3-year follow-up}

Table 7 displays the eight different options that we considered here as possible definitions of good outcome, along with the frequency of their occurrence. The results show that if we take the most stringent definition of good outcome (i.e. improvement on all four key outcomes) no patient came into this category. At the other end of the spectrum, the least stringent definition gave the maximum number of patients with a good outcome $(24 \%)$ by using relatively modest criteria, namely that there is an improvement in at least one of four outcome measures. Interestingly, this outcome was equally frequent when rated either by staff (row G) or by patients (row H). Between these extremes, definitions that might be considered as clinically meaningful are those shown in rows $\mathrm{C}$ or $\mathrm{D}$, in which a good outcome means that at least one measure improves

Table 7 Different definitions $(\mathrm{A}-\mathrm{H})^{\prime}$ of good outcome and the frequencies of their occurrence $(n=86)$

\begin{tabular}{|c|c|c|c|}
\hline & Staff-rated outcomes & Patient-rated outcomes & Patients \\
\hline & $\begin{array}{l}\text { Symptoms (BPRS) and functioning } \\
\text { (GAF) }\end{array}$ & $\begin{array}{l}\text { Needs (CAN) and quality of life } \\
\text { (LQoLP) }\end{array}$ & \\
\hline A & Both outcomes improved & Both outcomes improved & $0(0 \%)$ \\
\hline B & $\begin{array}{l}\text { One outcome improved, the other } \\
\text { stable }\end{array}$ & $\begin{array}{l}\text { One outcome improved, the other } \\
\text { stable }\end{array}$ & $9(10 \%)$ \\
\hline C & $\begin{array}{l}\text { One outcome improved, the other } \\
\text { stable }\end{array}$ & Neither is worsened & $18(21 \%)$ \\
\hline D & Neither is worsened & $\begin{array}{l}\text { One outcome improved, the other } \\
\text { stable }\end{array}$ & 15 (I7\%) \\
\hline$E$ & Both outcomes improved & Not considered & $5(6 \%)$ \\
\hline $\mathrm{F}$ & Not considered & Both outcomes improved & 6 (7\%) \\
\hline G & $\begin{array}{l}\text { One outcome improved, the other } \\
\text { stable }\end{array}$ & Not considered & $21(24 \%)$ \\
\hline $\mathrm{H}$ & Not considered & $\begin{array}{l}\text { One outcome improved, the other } \\
\text { stable }\end{array}$ & $21(24 \%)$ \\
\hline
\end{tabular}

BPRS, Brief Psychiatric Rating Scale; GAF, Global Assessment of Functioning; CAN, Camberwell Assessment of Need; LQoLP, Lancashire Quality of Life Profile.

I. Definitions A-H are not mutually exclusive.

Table 8 Different definitions $(A-H)^{\prime}$ of poor outcome and the frequencies of their occurrence $(n=86)$

\begin{tabular}{|c|c|c|c|}
\hline & Staff-rated outcomes & Patient-rated outcomes & \\
\hline & $\begin{array}{l}\text { Symptoms (BPRS) and functioning } \\
\text { (GAF) }\end{array}$ & $\begin{array}{l}\text { Needs (CAN) and quality of life } \\
\text { (LQoLP) }\end{array}$ & \\
\hline A & Both outcomes worsened & Both outcomes worsened & $3(3 \%)$ \\
\hline B & $\begin{array}{l}\text { One outcome worsened, the other } \\
\text { stable }\end{array}$ & $\begin{array}{l}\text { One outcome worsened, the other } \\
\text { stable }\end{array}$ & $8(9 \%)$ \\
\hline C & $\begin{array}{l}\text { One outcome worsened, the other } \\
\text { stable }\end{array}$ & Neither is improved & $23(27 \%)$ \\
\hline D & Neither is improved & $\begin{array}{l}\text { One outcome worsened, the other } \\
\text { stable }\end{array}$ & $14(16 \%)$ \\
\hline$E$ & Both outcomes worsened & Not considered & $13(15 \%)$ \\
\hline $\mathrm{F}$ & Not considered & Both outcomes worsened & $9(10 \%)$ \\
\hline G & $\begin{array}{l}\text { One outcome worsened, the other } \\
\text { stable }\end{array}$ & Not considered & $27(31 \%)$ \\
\hline $\mathrm{H}$ & Not considered & $\begin{array}{l}\text { One outcome worsened, the other } \\
\text { stable }\end{array}$ & $16(19 \%)$ \\
\hline
\end{tabular}

BPRS, Brief Psychiatric Rating Scale; GAF, Global Assessment of Functioning; CAN, Camberwell Assessment of Need; LQoLP, Lancashire Quality of Life Profile.

I. Definitions A-H are not mutually exclusive.

while none deteriorates. Again it is noteworthy that the frequency of this type of good outcome was closely similar whether rated by staff $(21 \%)$ or by patients $(17 \%)$. In overview, taking these more modest definitions of good outcome, between one in four and one in five patients had a good outcome at the 3-year follow-up.

Turning to poor outcome, Table 8 shows the corresponding combinations of criteria to define poor outcome and their frequency of occurrence. Again, with the narrowest definition (i.e. all four outcomes showing deterioration) this type of poor outcome was rare $(3 \%)$. The most permissive criteria, in which only one measure shows deterioration, applied to $31 \%$ when using staff ratings (row $\mathrm{G}$ ) and $19 \%$ when using patient ratings (row $\mathrm{H}$ ). The equivalent intermediate definition to that used 
for good outcome above, namely one measure deteriorates and none improves, shows that $27 \%$ of cases fulfilled these criteria when rated by staff (row D) and $16 \%$ when rated by patients (row C). Interestingly, the staff ratings were uniformly more pessimistic than the patient ratings.

\section{DISCUSSION}

The advantages of this study over previous work are: a carefully identified cohort of patients who were representative of all those living in a defined catchment area who were treated by specialist mental health services and who received comprehensive treatment in settings that prioritised the continuity of care; the use of standardised measures of outcome in four key domains collected in routine clinical services; the inclusion of both clinician-rated and patient-rated outcomes; and the combination of data collected about individual patients with longitudinal service utilisation data for those same patients, provided by the local psychiatric case register. These data therefore enable us to assess the degree to which these multiple domains and multiple perspectives show homogeneity or heterogeneity in the outcomes of schizophrenia.

There are two main limitations of this study. The first of these is that the sample was of treated prevalence cases, to establish the outcomes of care, and does not include cases of schizophrenia out of contact with public services or those not in contact with any service. However, previous research in South Verona has shown that very few such patients are treated in private hospitals or in private office practice alone (Tansella, 1993; Balestrieri et al, 1994). Moreover, it is standard practice for general practitioners to refer all psychosis cases to the state mental health services; such specialist services are free at the point of use and have been established since 1978, so it is unlikely that current cases remain out of care. The second limitation is sample size. Although inclusive of all prevalent cases in the service assessed, sample size was relatively small and for this reason we restrict ourselves to the two specific hypotheses and treat the other study aim as allowing exploratory analyses that may be hypothesis-generating. In addition, even if the set of predictors and outcome variables used in this study is one of the most comprehensive ever used, other important predictors (such as major life events, expressed emotion, adherence to prescribed treatment and use of street drugs) or outcomes (such as self-injurious and suicidal behaviours, the use of emergency and crisis intervention services) were not included in the analysis. Finally, in this study predictive patterns have been identified that reflect statistical associations between variables measured on subsequent occasions. Caution should be used in considering the associations found as being representative of causation mechanisms.

\section{Changes occurring at 3 years}

The first hypothesis set in this study was that, at the level of the whole cohort, there would be no significant deterioration in terms of psychopathology and subjective quality of life. The results require us to reject this hypothesis with regard to psychopathology because the mean symptom severity level for the whole group showed a worsening that is more clear-cut in the case of negative symptoms. Because quality-of-life scores show no significant change over the study period, data obtained confirmed this part of the hypothesis, both in the overall LQoLP score and in the various life domains.

The second hypothesis was that there would be significant deterioration in terms of functioning and patient-rated needs. A trend towards deterioration of functioning was found, although it was not statistically significant owing to the large variation and the small sample size. For these reasons we must reject the second hypothesis with regard to functioning. Concerning the needs for care, overall the total number of needs did not show a significant decrease; however, social and health needs decreased significantly and functioning needs increased. The ratio of met:unmet needs at baseline was especially unfavourable in the case of social needs. At follow-up it tended to worsen further in all domains except basic needs, indicating that needs that continue to be present over time tend to worsen, the most clear-cut worsening being in functioning needs. With regard to needs for care, our findings did not confirm the second hypothesis but pointed to a complex picture where both failure and success of services in meeting patients' needs were detected, with the areas of social and functioning needs appearing to be the more critical ones.

Moving to the individual patient analyses, for staff-rated outcomes the results showed that for symptoms the majority of patients $(74 \%)$ remained stable, whereas for functioning only $23 \%$ did so. In relation to the consumer-rated outcomes, patients who had no needs at baseline maintained the same condition in $>80 \%$ of cases at follow-up, and this was true for all CAN domains. In those patients who had needs at baseline, a trend for improvement was detected over time in all areas, with the exception of social needs, where a considerable proportion of needs remained stable or their severity tended to worsen. For quality of life a consistent pattern emerged in which about half of the patients remained stable, a quarter improved and a quarter deteriorated. By these individual outcome domains, therefore, considerable heterogeneity was demonstrated in the 3-year treated outcomes.

\section{Predictors of outcome}

The second aim of the study was to develop a model to predict the outcomes for individuals with schizophrenia in nonexperimental clinical settings. The results found that such models could explain 32$42 \%$ of the variance in the four key outcome variables. Although functioning, number of days of hospital admission and unemployment were each identified as significant predictors in two or more of the four models, there was no consistent overall pattern of variables that predicted all outcomes. These results suggest that different outcomes have, to some extent, different and specific predictors and support the view that schizophrenia outcome is a complex and multi-dimensional function (Strauss \& Carpenter, 1977); as a consequence, it may be hypothesised that different types of intervention (e.g. increasing employment rates among individuals with schizophrenia) may differentially affect some outcomes more than others.

\section{Good and poor multi-dimensional outcomes}

The third aim was to undertake exploratory analyses to assess the frequency of occurrence of 'good' and 'poor' outcome for this cohort. For this purpose a series of different definitions of 'good' and 'poor' outcome have been considered that use explicit combinations of the four outcome measures. This approach has produced a clear result, in that staff ratings of poor outcome are more common than patient ratings of 
poor outcome. By comparison, the most inclusive definitions, requiring that one variable improved and the other from either the staff or the patient perspective remained stable, indicated that $24 \%$ of cases had 'good' outcome and $19-31 \%$ had 'poor' outcome. It is noteworthy that the gradient of frequencies of occurrence for these varying definitions was the same for both good and poor outcome combinations of variables.

These findings lead us to the view that there may be partially overlapping but distinct domains that can be identified as legitimate outcomes for schizophrenia. Such different domains may not covary directly, they may be influenced by at least partially separate predictors and they may reveal different rates of poor and good outcome depending upon which we accord primacy.

In particular, we consider that the distinction between staff-rated and patient-rated outcome measures warrants further and more detailed investigation. Some comparisons of the patterns and frequencies of outcome using different perspectives have been made (Slade et al, 1998; Lasalvia et al, 2000; Hansson et al, 2001) but multiple-perspective research in the field of mental health is still in its infancy. Such an approach may give greater weight to the view of many patients that treatments and services should give strong emphasis to social as well as pharmacological and psychological approaches, a view reinforced by our own results on unmet needs in this study. In this case, additional treatments targeted at problem areas beyond symptoms become especially important because they may offer more opportunities to reduce disability and to increase quality of life and subjective well-being. This study therefore opens up lines of scientific enquiry to investigate the heterogeneity of outcomes when measured across multiple dimensions and when rated from different perspectives.

\section{ACKNOWLEDGEMENTS}

We are grateful to the patients who participated in the study. We are indebted to the colleagues who contributed to the assessments and specifically thank Giovanni Salvi, Francesca Malchiodi, Antonella Miletti, Alberto Parabiaghi and Benedetta Stefani. We are most grateful to Doriana Cristofalo for assistance in data management.

\section{CLINICAL IMPLICATIONS}

- There is a marked heterogeneity in the outcomes of schizophrenia, depending on the domain considered. Clinicians should take this complex picture into account when planning and evaluating therapeutic strategies.

- Negative symptoms should be assessed regularly in patients with schizophrenia who are treated by mental health services, because they may worsen more often than the other symptoms.

- Special attention should be paid to persistent social and functioning needs for care because they tend to be (or become) unmet more often than other needs.

\section{LIMITATIONS}

Only people with schizophrenia attending public services in the catchment area have been included in the study.

- The sample size, although inclusive of all prevalence cases in the service assessed, is relatively small and for this reason we restrict ourselves to two specific hypotheses and treat the other study aims as allowing exploratory analyses that may be hypothesis-generating.

- This is a naturalistic study of outcome of schizophrenia in a community-based setting; no comparison with treatment outcome obtained in other types of setting is provided.

MIRELLA RUGGERI, MD, PhD, ANTONIO LASALVIA, MD, PhD, MICHELE TANSELLA, MD,

CHIARA BONETTO, DrStat, PhD, MARIA ABATE, MD, Department of Medicine and Public Health, Section of Psychiatry, University of Verona, Italy; GRAHAM THORNICROFT, MD, PhD, Section of Community Psychiatry (PRiSM), Health Service Research Department, Institute of Psychiatry, London, UK; LILIANA ALLEVI, MD, PAOLA OGNIBENE, MD, Department of Medicine and Public Health, Section of Psychiatry, University of Verona, Italy

Correspondence: Mirella Ruggeri, Dipartimento di Medicina e Sanitá Pubblica, Sezione di Psichiatria, Universitá di Verona, Ospedale Policlinico, 37134 Verona, Italy. Tel: +39045 8074441 ; fax: + 390455858 7I; e-mail: mirella.ruggeri@univr.it

(First received 24 March 2003, final revision 25 July 2003, accepted 12 August 2003)

\section{REFERENCES}

American Psychiatric Association (1987) Diagnostic and Statistical Manual of Mental Disorders (3rd edn, revised) (DSM-III-R). Washington, DC: APA.

Balestrieri, M., Bon, M. G. \& Rodriguez-Sacristan, A., et al (1994) Pathways to psychiatric care in southVerona, Italy. Psychological Medicine, 24, 64I-649.

Becker, T., Knapp, M., Knudsen, H. C., et al (1999) The EPSILON study of schizophrenia in five European countries. Design and methodology for standardising outcome measures and comparing patterns of care and service costs. British Journal of Psychiatry, 175, 514-521.

Boardman, A. P., Hodgson, R. E., Lewis, M., et al (1999) North Staffordshire Community Beds Study: longitudinal evaluation of psychiatric in-patient units attached to community mental health centres. I:
Methods, outcome and patients satisfaction. British Journal of Psychiatry, 175, 70-78.

Carpenter, W. T. Jr \& Strauss, J. S. (1991) The prediction of outcome in schizophrenia. IV: Eleven-year follow-up of the Washington IPSS cohort. Journal of Nervous and Mental Disease, 179, 517-525.

Drake, R. E., Mueser, K. T., Torrey, W. C., et al (2000) Evidence-based treatment of schizophrenia. Current Psychiatry Report, 2, 393-397.

Endicott, J., Spitzer, R. L., Fleiss, J. L., et al (1976) The Global Assessment of Functioning scale. A procedure for measuring overall severity of psychiatric disturbance. Archives of General Psychiatry, 33, 766-77I.

Gaite, L., Vázquez-Barquero, J. L., Arriaga Arrizabalaga, A., et al (2000) Quality of life in schizophrenia: development, reliability and internal consistency of the Lancashire Quality of Life Profile - 
European Version. EPSILON Study 8. British Journal of Psychiatry, 177 (suppl. 39), s49-s54.

Gaite, L., Vázquez-Barquero, J. L., Borra, C., et a (2002) Quality of life in patients with schizophrenia in five European countries: the EPSILON study. Acto Psychiatrica Scandinavica, 105, 283-292.

Hansson, L., Vinding, H. R., Mackeprang, T., et a (200I) Comparisons of key worker and patient assessment of needs in schizophrenic patients living in the community: a Nordic multicentre study. Acta Psychiatrica Scandinavica, 103, 45-51.

Harrison, G., Hopper, K., Craig, T., et al (200I) Recovery from psychotic illness: a 15- and 25-year international follow-up study. British Journal of Psychiatry, 178, 506-517.

Harrow, M., Sands, J. R., Silverstein, M. L., et al (1997) Course and outcome for schizophrenia versus other psychotic patients: a longitudinal study Schizophrenia Bulletin, 23, 287-303.

Institute of Medicine (200I) Crossing the Quality Chasm: a New Health System for the 2Ist Century. Washington, DC: Institute of Medicine.

Jablensky, A., Sartorius, N., Ernberg, G., et al (1992) Schizophrenia: manifestations, incidence and course in different cultures. A World Health Organization tencountry study. Psychological Medicine Monograph Supplement, 20, I-97.

Lasalvia, A., Ruggeri, M., Mazzi, M. A., et al (2000) The perception of needs for care in staff and patients in community-based mental health services. The SouthVerona Outcome Project 3. Acta Psychiatrica Scandinavica, 102, 366-375.

Leese, M., Johnson, S., Slade, M., et al (1998) User perspective on needs and satisfaction with mental health services. PRiSM Psychosis Study. 8. British Journal of Psychiatry, I73, 409-4I5.
Leff, J., Sartorius, N., Jablensky, A., et al (1992) The International Pilot Study of Schizophrenia: five-year follow-up findings. Psychological Medicine, 22, |3|-145.

Lehman, A. F. \& Steinwachs, D. M. (1998) Translating research into practice: the Schizophrenia Patient Outcomes Research Team (PORT) treatment recommendations. Schizophrenia Bulletin, 24, I-10.

Lukoff, D., Liberman, R. P. \& Nuechterlein, K. H. (1986) Symptom monitoring in the rehabilitation of schizophrenic patients. Schizophrenia Bulletin, 12 578-602.

Mason, P., Harrison, G., Glazebrook, C., et al (1996) The course of schizophrenia over 13 years. A report from the International Study on Schizophrenia (ISoS) coordinated by the World Health Organization. British Journal of Psychiatry, 169, 580-586.

McCrone, P., Leese, M., Thornicroft, G., et al (2000) Reliability of the Camberwell Assessment of Need European Version. EPSILON Study 6. British Journal of Psychiatry, 177 (suppl. 39), s34-s40.

Oliver, J. P. (1991) The social care directive: development of a quality of life profile for use in community services for the mentally ill. Social Work and Social Science Review, 3, 4-45.

Pope, H. G., lonescu-Pioggia, M. \& Pope, K.W. (200I) Drug use and life style among college undergraduates: a 30-year longitudinal study. American Journal of Psychiatry, 158, 1519-1521.

Ruggeri, M., Bisoffi, G., Fontecedro, L., et al (200I) Subjective and objective dimensions of quality of life in psychiatric patients: a factor analytical approach. The South Verona Outcome Project 4. British Journal of Psychiatry, 178, 268-275.

Singh, S. P., Croudace, T., Amin, S., et al (2000) Three-year outcome of first-episode psychoses in an established community psychiatric service. British Journal of Psychiatry, 176, 210-216.
Slade, M., Phelan, M. \& Thornicroft, G. (1998) A comparison of needs assessed by staff and by an epidemiologically representative sample of patients with psychosis. Psychological Medicine, 28, 543-550.

Slade, M., Thornicroft, G., Loftus, L., et al (1999) CAN: The Camberwell Assessment of Need. London: Gaskell.

Strauss, J. S. \& Carpenter, W. T. Jr (1977) Prediction of outcome in schizophrenia. III. Five-year outcome and its predictors. Archives of General Psychiatry, 34, 159-163.

Tansella, M. (1993) The Research Unit of the Servizio di Psicologia Medica at the Institute of Psychiatry of the University of Verona, 1980-1991. Psychological Medicine 23, 239-247.

Vázquez-Barquero, J. L., Cuesta, M. J., Herrera, Castanedo S., et al (1999) Cantabria first-episode schizophrenia study: three-year follow-up. British Journal of Psychiatry, 174, 141-149.

Ventura, J., Green, M., Schaner, A., et al (1993) Training and quality assurance with the Brief Psychiatric Rating Scale. The 'drift busters'. International Journal of Methods in Psychiatric Research, 3, 221-244.

Wiersma, D., Nienhuis, F. J., Slooff, C. J., et al (1998a) Natural course of schizophrenic disorders: a 15-year follow-up of a Dutch incidence cohort. Schizophrenia Bulletin, 24, 75-85.

Wiersma, D., Nienhuis, F. J., Giel, R., et al (1998b) Stability and change in needs of patients with schizophrenic disorders: a 15 and 17-year follow-up from first onset of psychosis, and a comparison between 'objective' and 'subjective' assessments of needs for care. Social Psychiatry and Psychiatric Epidemiology, 33, 49-56.

World Health Organization (1992) Schedules for Clinical Assessment in Neuropsychiatry. Geneva: WHO. 